\title{
Pouch surgery - The importance of the transitional zone
}

\author{
IC LAVERY, MBBS, FRACS, WB TUCKSON, MD, VW FAZIO, MBBS, FRACS, JR OAKLEY, MBBS, FRACS, \\ JM CHURCH, MB, CHB, MMEDSCI, FRACS, JW MILSOM, MD
}

\begin{abstract}
Patients with preservation of the transitional zone of the anal canal have less leakage and less need to wear pads than patients who have had mucosectomy. There is a significant difference in mean maximum resting pressure between patients that have had anal transitional zone preservation and mucosectomy. With preservation of the anal transitional zone, a mean maximum resting pressure of $57.6 \pm 3.8 \mathrm{mmHg}$ was obtained compared with $47.3 \pm 4 \mathrm{mmHg}$ in the mucosectomy group. Preservation of the resting pressure is dependent on preservation of internal anal sphincter integrity. The integrity of the sphincter is injured during mucosectomy due to anal dilation. Other factors affecting continence and stool frequency, such as diet, antidiarrheal medications, stool consistency and compliance, when examined were found to be unrelated factors. Can J Gastroenterol 1990;4(7):428-431
\end{abstract}

Key Words: lleo-anal anastomosis, Pressure studies, Surgery

\section{Les 'ostomies' - Importance de la zone de transition}

RESUME: Les patients chez qui la zone de transition du canal anal a été préservée souffrent d'un nombre moindre de fuites et éprouvent moins le besoin de porter des tampons que les patients qui ont subi une mucosectomie. Il existe une différence significative entre les deux groupes quant à la pression maximum moyenne de repos. Dans le groupe chez qui la zone de transition anale a été préservée, la pression maximum moyenne du sphincter au repos était de $57,6 \pm 3,8$ $\mathrm{mm} \mathrm{Hg}$ par rapport à $47,3 \pm 4 \mathrm{~mm} \mathrm{Hg}$ dans le groupe ayant subi une mucosectomie. La préservation de la pression de repos dépend de l'intégrité du sphincter anal interne. Or, la mucosectomie inflige un traumatisme direct au sphincter anal lors de sa dilatation. D'autres facteurs influant sur la continence et la fréquence des selles (régime alimentaire, antidiarrhéiques, consistence des selles et compliance) ont été examinés mais ne semblent pas intervenir.

The Cleveland Clinic Foundation, Department of Colorectal Surgery, Cleveland, Ohio

Correspondence and reprints: Dr IC Lavery. The Cleveland Clinic Foundation, Department of Colorectal Surgery, One Clinic Center, 9500 Euclid Avenue, Cleveland, OH 44195-5044. USA
I N THE CONTINUING EFFORT TOREstore normal bowel function to patients after proctocolectomy for ul. cerative colitis, the ileal pouch-anal anastomosis is, at present, the procedure of choice. Patients prefer a pelvic pouch rather than an ileostomy, even though the functional results of the pel. vic pouch are not perfect $(1,2)$. Patients have an increased frequency of defecation $(1,3)$, and often require dietary and pharmacologic manipulation to alter intestinal transit time (4). The greatest concern to patients is loss of continence $(5,6)$. Leakage of stool has been reported in up to one-half of patients during the day or night $(2,7,8)$.

Incontinent patients have lower maximum anal resting pressures than those who are continent $(3,9)$. Maximum anal resting pressures are de. creased by anal retraction during mucosal proctectomy $(8,10)$ or the transanal insertion of sutures (11). Preservation of the anal transitional zone has been advised to avoid mucosal proctectomy and decrease leakage (12. 14).

\section{PATIENTS AND METHODS}

Functional results and manometric data are presented on 221 patients who have undergone ileal pouch-anal anas. 
TABLE 1

Diagnosis and technique of ileal pouch-anal anastomosis

\begin{tabular}{lcc}
\hline & Preservation transitional zone & Mucosectomy \\
\hline Mucosal ulcerative colitis & 96 & 88 \\
Crohn's colitis & 7 & 10 \\
Indeterminate colitis & 1 & 0 \\
Familial polyposis & 7 & 12 \\
Total & 111 & 110 \\
\hline
\end{tabular}

TABLE 2

Functional results of 221 patients following ileal pouch-anal anastomosis

\begin{tabular}{lcc}
\hline & $\begin{array}{c}\text { Function preservation } \\
\text { transitional zone }\end{array}$ & Mucosectomy \\
\hline Frequency (median) & 6 & 6 \\
Stools per $24 \mathrm{~h}$ & 1 & 1 \\
Stools at night & 6 & 16 \\
Leakage (\%) & 14 & 49 \\
Minor during the day & 2 & 3 \\
Minor at night & 2 & 15 \\
Major during the day & 10 & 12 \\
Major at night & 10 & 41 \\
Pads during the day & & \\
Pads at night & & \\
\hline
\end{tabular}

tomosis following proctocolectomy. One hundred and ten had mucosectomy and 111 had preservation of the anal transitional zone, with either a stapled anastomosis or a hand-sewn anastomosis. The diagnosis for which the procedure was performed and the method are shown in Table 1. The pouches were either of the J or S configuration.

Function was assessed by a telephone or personal interview. Information was collected on the frequency of defecation, continence and the use of pads. Incontinence has been defined as: minor leakage producing a stain 3 $\mathrm{cm}$ in diameter at least three times a week; major leakage producing a stain greater than $3 \mathrm{~cm}$, or the involuntary passage of a bowel movement at least twice a month.

Anal manometry was performed with a water-perfused Arndorfer catheter modified with four sensor ports radially oriented at $90^{\circ}, 7 \mathrm{~cm}$ from the tip. Two sensor ports at the tip of the catheter are enclosed in a $500 \mathrm{~mL}$ latex balloon. Hard copies are generated on a Narco HHS 200 recorder and amplifier. The station pull-through technique was used beginning $5 \mathrm{~cm}$ proximal to the anal verge with resting and squeeze pressures recorded before advancing the catheter. The pressures from the four quadrants at each of the stations were averaged and the highest recorded as either maximum resting pressure or maximum squeeze. Anal canal length was determined as the length of the anal canal in which resting pressures equalled or exceeded $20 \mathrm{mmHg}$. The maximum tolerated volume was taken as the volume infused into the pouch when the patient felt either an intense urge to defecate or pain that prevented further distension. Compliance was recorded as the pressure in the pouch minus the balloon pressure at the maximum tolerated volume.

Operative technique: The transitional zone was preserved by performing the proctocolectomy in the lithotomyTrendelenburg position using LloydDavies stirrups. The proctocolectomy was performed in a conventional manner with the rectum being mobilized to the levator ani and transsected at the top of the anal canal at the anorectal ring. A purse-string suture was placed in the upper end of the anal canal and the stapled anastomosis performed with a circular stapling instrument introduced transanally. A proximal loop ileostomy was fashioned and closed 12 weeks after the construction of the pouch, in the absence of complications.

Mucosectomy was performed using a Pratt bivalved anal speculum after infiltrating the submucosa with 1:200,000 adrenaline solution. The mucosa was stripped from the dentate line cephalad to the level of muscle transsection. The anastomosis between the pouch and the dentate line was performed by interrupted sutures to the cut edge of the mucosa at the dentate line.

Statistical analysis: When appropriate, either the paired or unpaired Student's $t$ test and $\chi^{2}$ test was used for data analysis.

\section{RESULTS}

Functional results are shown in Table 2.

Stool frequency: The frequency of defecation was no different in either group. The median $24 \mathrm{~h}$ frequency was six with one stool occurring at night. Leakage: Leakage rates were different between the two groups, both day and night. Minor leakage occurred in $6 \%$ of patients with preservation of the transitional zone and $16 \%$ of patients who had mucosectomy $(\mathrm{P}<0.05)$. At night the incidence of minor leakage was $14 \%$ in patients with preservation of the transitional zone and $43 \%$ in those with mucosectomy $(\mathrm{P}<0.001)$. Major leakage occurred in $2 \%$ of the patients with preservation of the transitional zone during daytime or at night. Three per cent of the patients who had mucosectomy had major leakage during the day and 15\% at night. The difference in the incidence of leakage at night was significant $(\mathrm{P}<0.001)$.

Pad use: Ten per cent of the patients that had preservation of the transitional zone and $12 \%$ of those with mucosectomy wore pads during the daytime (not significant). However, there was a significant difference in the use of pads at night: $10 \%$ of those with preservation of the transitional zone compared with $41 \%$ with mucosectomy $(\mathrm{P}<0.001)$. The identical day rates of leakage may be related to the conscious reinforcement of the external anal sphincters. 
TABLE 3

\section{Postoperative manometric data}

\begin{tabular}{lcc}
\hline & $\begin{array}{c}\text { Preservation } \\
\text { transitional zone }\end{array}$ & Mucosectomy \\
\hline Anal canal length $(\mathrm{cm})$ & $2.9 \pm 0.3$ & $2.8 \pm 0.3$ \\
Rectal anal inhibitory reflex $(\%)$ & 23 & 16 \\
Maximum resting pressure $(\mathrm{mmHg})$ & $57.6 \pm 3.8$ & $47.3 \pm 4$ \\
Maximum squeeze pressure $(\mathrm{mmHg})$ & $208 \pm 20$ & $205 \pm 22$ \\
Maximum tolerated volume $(\mathrm{mL})$ & $261 \pm 28$ & $253 \pm 24$ \\
Compliance & $13.5 \pm 2.4$ & $10.9 \pm 1.8$ \\
\hline
\end{tabular}

Compliance is the pressure in the pouch minus the balloon pressure at the maximum tolerated volume

\section{TABLE 4}

\section{Complications following ileal pouch-anal anastomosis}

\begin{tabular}{lcc}
\hline & $\begin{array}{c}\text { Preservation } \\
\text { transitional zone }\end{array}$ & Mucosectomy \\
\hline lleal pouch-anal anastomosis stricture & 4 & 11 \\
lleal pouch-anal anastomosis leak & 0 & 2 \\
Anal vaginal fistula & 1 & 2 \\
Perianal abscess & 0 & 1 \\
Perianal fistula & 0 & 5 \\
Pelvic abscess & 1 & 5 \\
\hline
\end{tabular}

Anal canal length: There was no difference in the length of the anal canal in either group. There was no significant difference in the number of patients that had preservation of the rectal anal inhibitory reflex in either group postoperatively (Table 3 ). There was no difference in the ability of the patients to discriminate gas from stool. Maximum resting pressure: The maximum resting pressure with preservation of the transitional zone was $57.6 \pm 3.8$ $\mathrm{mmHg}$, and in the mucosectomy group $47.3 \pm 4 \mathrm{mmHg}(\mathrm{P}<0.005)$. The difference in the maximum resting pressure between the two groups was significant $(\mathrm{P}<0.005)$ (Table 3$)$.

Maximum squeeze pressure: The maximum squeeze pressure was $208 \pm 20$ $\mathrm{mmHg}$ in the group with preservation of the transitional zone and $205 \pm 22$ $\mathrm{mmHg}$ in the mucosectomy group (not significant) (Table 3).

Maximum tolerated volume: The maximum tolerated volume was $261 \pm 28 \mathrm{~mL}$ in the group with preservation of the transitional zone and $253 \pm 24 \mathrm{~mL}$ in the mucosectomy group (not significant).

Compliance: There was a difference in pouch compliance: $13.5 \pm 2.4$ in the group with preservation of the transitional zone and $10.9 \pm 1.8$ in the mucosectomy group. This is a reflection of pouch configuration. More patients in the group with preservation of the transitional zone had $\mathrm{S}$ pouches than J pouches. $\mathrm{S}$ pouches in general have a higher degree of compliance.

Complications: The mucosectomy group had more anastomotic and pelvic complications than the group with preservation of the anal transitional zone (Table 4).

\section{DISCUSSION}

Fewer patients in the group with preservation of the anal transitional zone had minor leakage during the day or night than the mucosectomy group. They also used fewer pads at night than the mucosal proctectomy group (Table 2). There was a significant difference in the mean maximum resting pressure between the groups. The group with preservation of the anal transitional zone had a mean maximum resting pressure of $57.6 \pm 3.8 \mathrm{mmHg}$ and the mucosectomy group $47.3 \pm 4 \mathrm{mmHg}$. The relationship between incontinence and low mean maximum resting pressures has been identified by other authors $(3,9,14)$. Preservation of resting pressure is dependent upon preservation of internal anal sphincter integrity. The internal anal sphincter is injured during mucosectomy due to anal dilation $(3,9)$. The authors' observation in this assessment of their patients supports the observations made earlier (12-14). Patients who have stapled ileal pouch-anal anastomoses without endoanal mucosal proctectomy have higher maximum resting pressure values and a lower in. cidence of incontinence than patients who have had endoanal mucosal proc. tectomy.

Patients who have preservation of the transitional zone of the anal canal have less leakage and consequently less need to use pads than those that have had a mucosectomy.

Other factors affecting continence and stool frequency are the patient's diet, antidiarrheal medication, stool consistency and pouch compliance. There was no difference between groups when these factors are considered. There was no difference in anal canal length, maximum squeeze pres. sure or maximum tolerated volume. The significant difference noted was in mean maximum resting pressure which is dependent upon internal anal sphincter tone. It appears that preservation of the transitional zone without anal manipulation is important in maintaining internal anal sphincter tone and consequently preservation of continence. Sensation in the maintenance of continence does not seem to be important in the study.

A cause for concern in retention of the transitional zone of the anal canal is the risk of development of carcinoma in retained colonic mucosa. Biopsies to date show that only a very small per. centage of the patients have colonic mucosa, and no patient has been found to have dysplasia or carcinoma. Kewenter et al (15) calculated the cumulative incidence of carcinoma in colitis when the whole colon was in. volved in extensive ulcerative colitis to be $34 \% 25$ years after the onset of colitis. Grundfest et al in an earlier report from the Cleveland Clinic (16) reported four rectal cancers arising in 84 patients with ileorectal anastomoses $(4.8 \%)$ followed for up to 30 years (mean 7.7). The cumulative risk of 
cancer development was zero at 10 years, $2.1 \%$ at 15 years, $5 \pm 3.5 \%$ at 20 years and $12.9 \pm 8.3 \%$ after 25 years of disease. Extrapolating further reduction in the mucosa at risk following proctectomy and pelvic pouch ileoanal anastomosis with preservation of the transitional zone, 'while the risk of developing cancer has yet to be calculated it must be very small.

\section{REFERENCES}

1. Nicholls RJ. Restorative proctocolectomy with various types of reservoir. World J Surg 1987:11:751-62.

2. Vasilevsky CA, Rothenberger DA, Goldberg SM. The S ileal pouch-anal anastomosis. World J Surg 1987;11:742-50.

3. Nasmyth DG, Johnston D, Godwin RG, Dixon MF, Smith A, Williams NS. Factors influencing bowel function after ileal pouch anal anastomosis. Br J Surg 1986;73:469-73.

4. Taylor BA, Dozois RR. The ileal pouch-anal anastomosis. World J Surg 1987;11:727-34.

5. McHugh SM, Diamant NE, McLeod $\mathrm{R}$, Cohen Z. S pouches versus ] pouches: A comparison of functional outcomes. Dis Colon Rectum 1987;30:671-7.

6. Becker JM, Hillard AE, Mann FA, Kestenberg A, Nelson JA. Functional assessment after colectomy, mucosal proctectomy and endorectal ileoanal pull through. World J Surg 1985;9:598-605.

\section{CONCLUSION}

The authors believe the operation of ileal pouch-anal anastomosis provides better functional results when anal manipulation (as occurs for a variable time when doing a mucosectomy) is minimized. The risk of cancer in the anorectal stump distal to the anastomosis is not entirely negated, but can be minimized and acceptably lowered

7. Pemberton JH, Phillips SF, Ready RR, Zinsmiester AR, Beahrs OH. Quality of life after Brooke ileostomy and ileal pouch-anal anastomosis: Comparison of performance status. Ann Surg 1989;209:620-8.

8. Williams NS, Marzouk DEMM, Hallan RI, Waldran DJ. Function after ileal pouch and stapled pouch-anal anastomosis for ulcerative colitis. $\mathrm{Br}$ J Surg 1989;76:1168-71.

9. O'Connell PR, Stryker SJ, Metcalf $\mathrm{AM}$, Pemberton JH. Anal canal pressure and motility after ileoanal anastomosis. Surg Gynecol Obstet 1988;166:47-54.

10. Snooks S, Henry MM, Swash M. Fecal incontinence after anal dilatation. $\mathrm{Br} \mathrm{J}$ Surg 1984:71:617-8.

11. Tuckson WB, Lavery IC, Fazio VW, Oakley JR, Church J, Milsom JW. Manometric and functional comparison of ileal pouch anal anastomosis with anal manipulation and without anal manipulation. Am J Surg. (In press)

12. Johnson D, Holdsworth PJ, Nasmyth by monitoring the anal transitional zone with annual biopsies to exclude or diagnose dysplasia early and by performing mucosectomy in those with a high risk of cancer, eg, synchronous colon cancer. The benefit of improved function that occurs with a stapled ileal pouch-anal anastomosis outweighs the theoretical risk of cancer in the retained anal transitional zone.

DC, et al. Preservation of the entire anal canal in conservative proctocolectomy for ulcerative colitis: A pilot study comparing end to end ileoanal anastomosis without mucosal resection and endo-anal anastomosis. Br J Surg 1987;74:940-4.

13. Heald RJ, Allen DR. Stapled ileo-anal anastomosis: A technique to avoid mucosal proctectomy in the ileal pouch operation. $\mathrm{Br} J$ Surg 1986;73:571-2.

14. Lavery IC, Tuckson WB, Easley KA. Internal anal sphincter function after total abdominal colectomy and stapled ileal pouch-anal anastomosis without mucosal proctectomy. Dis Colon Rectum 1989;32:950-3.

15. Kewenter J, AhIman H, Hulten L. Cancer risk in extensive ulcerative colitis. Ann Surg 1978;188:824-8.

16. Grundfest SF, Fazio VW, Weiss RA, et al. The risk of cancer following colectomy and ileorectal anastomosis for extensive mucosal ulcerative colitis. Ann Surg 1981;193:9-14. 


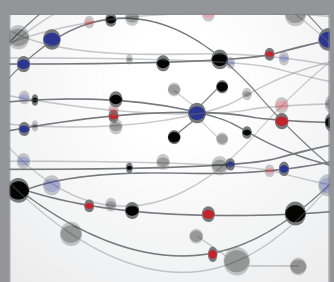

The Scientific World Journal
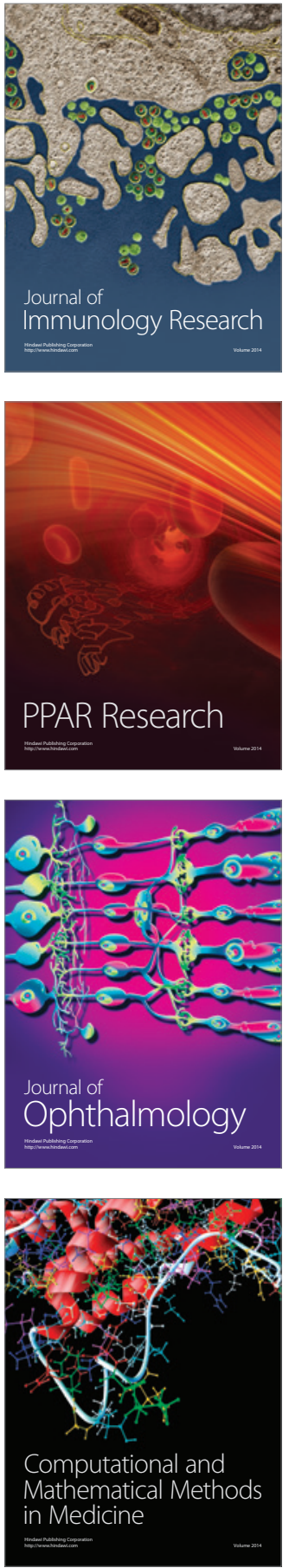

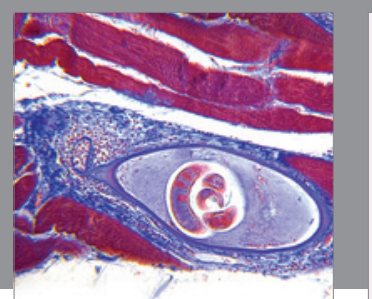

Gastroenterology Research and Practice

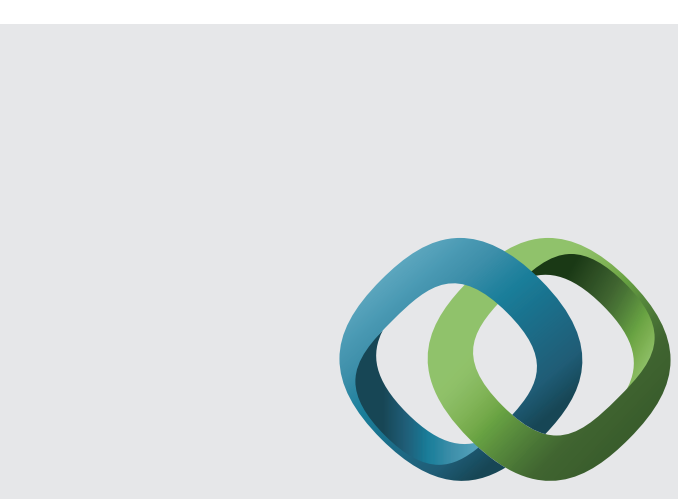

\section{Hindawi}

Submit your manuscripts at

http://www.hindawi.com
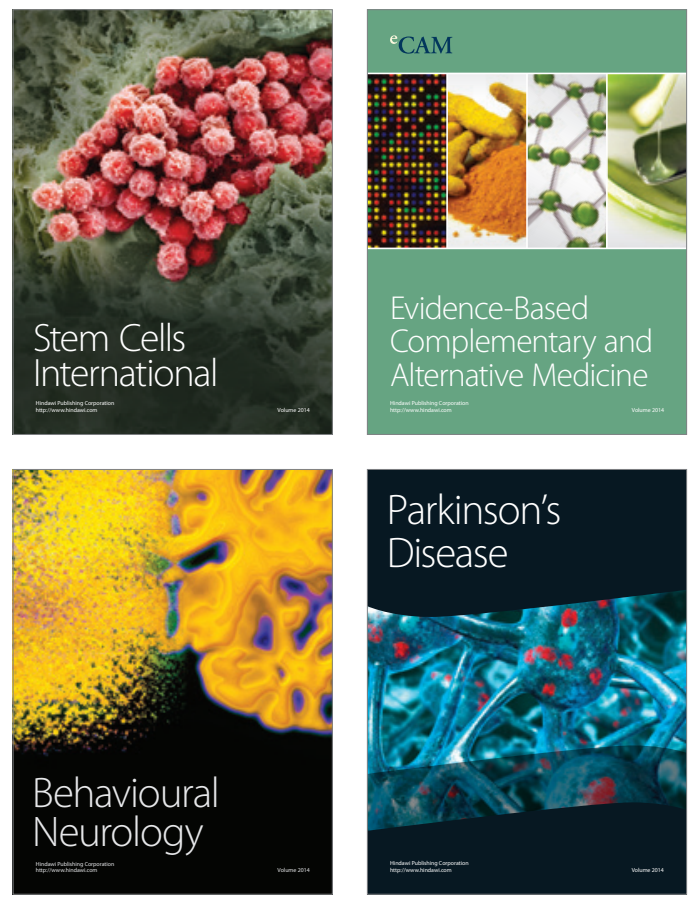
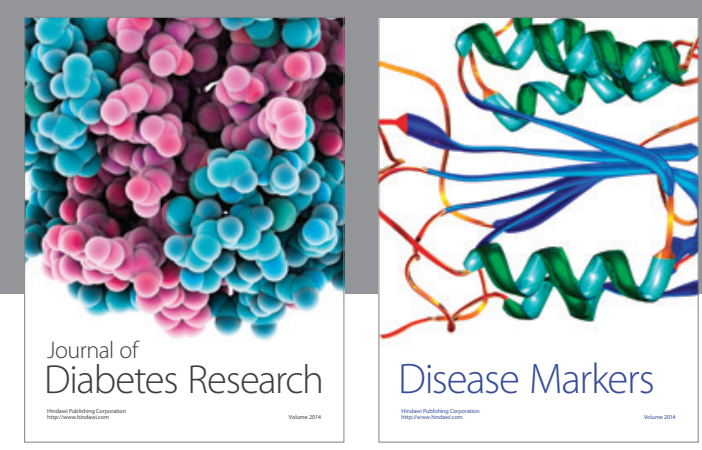

Disease Markers
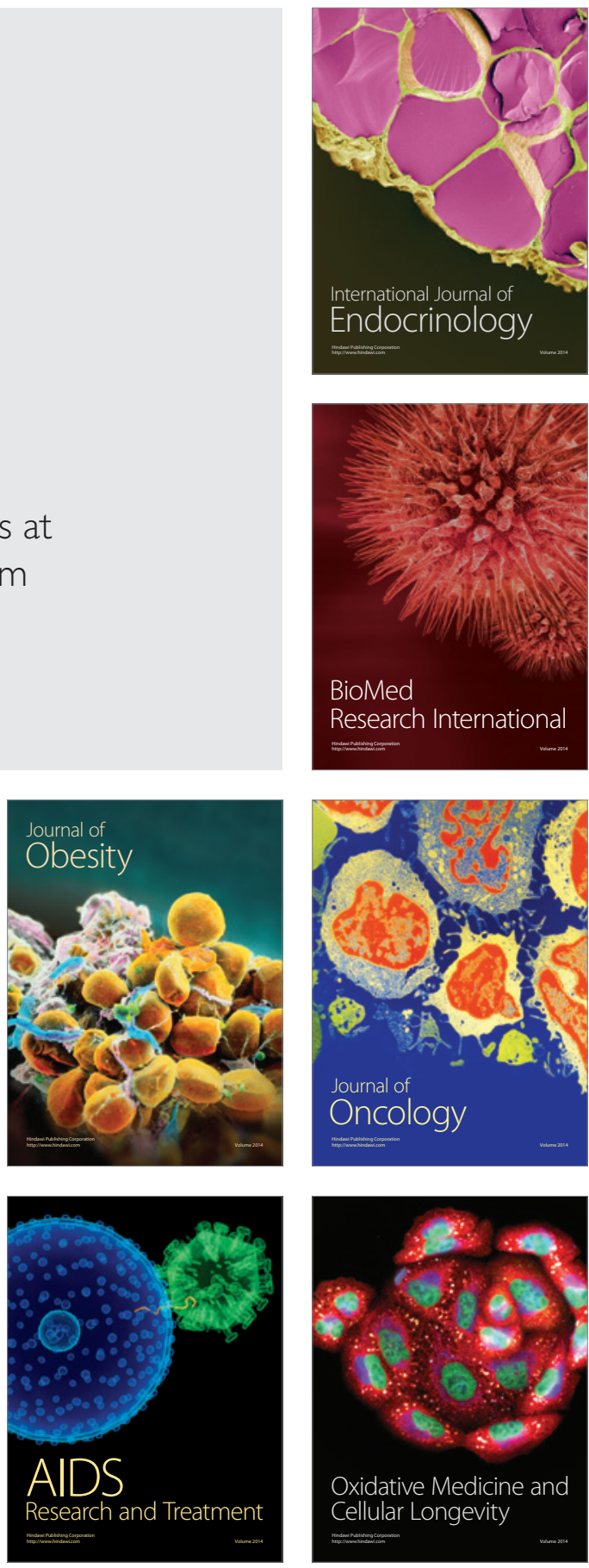